\title{
PROTOTIPE MODEL PEMBELAJARAN ON-LINE DENGAN METODE OBJECT ORIENTED BERBASIS WEB (STUDI KASUS MATA PELAJARAN LOGIKA MATEMATIKA)
}

\author{
Syahriani Syam ${ }^{1)}$, Mahmudin ${ }^{2)}$, Alman Fakhri ${ }^{3)}$, Rizky Fuadi ${ }^{4)}$, Ajeng Nurmaulida ${ }^{5)}$ \\ Teknik Informatika Universitas Islam Syekh-Yusuf Tangerang \\ Jl.Maulana Yusuf No.10 Babakan Kota Tangerang, Banten, 15118 Indonesia \\ Email : ssyam@unis.ac.id ${ }^{1)}$, mahmudin@unis.ac.id ${ }^{2}$, almanfakhri999@gmail.com ${ }^{3)}$, rizkifuadi62@gmail.com $^{4)}$
}

\begin{abstract}
ABSTRAK
Perkembangan teknologi informasi dan komunikasi (TIK) telah membawa perubahan yang sangat besar bagi dunia pendidikan. Bentuk perkembangan teknologi informasi dan komunikasi yang diterapkan di dunia pendidikan adalah metode pembelajaran online atau lebih dikenal dengan sebutan e-Learning yang membantu sebuah proses pembelajaran. Berawal dari adanya masalah pada motode pembelajaran dan minat belajar mahasiswa pada mata kuliah logika Matematika pada Fakultas Teknik UNIS Tangerang, maka dikembangkan suatu pembelajaran online (e-learning) dengan metode object oriented berbasis web mengunakan PHP dan MySQL. Dengan model pembelajaran online berbasis web ini dapat meningkatkan proses pembelajaran mahasiswa pada mata kuliah logika Matematika dan pembelajaran online memudakan Dosen memberikan materi pembelajaran serta memberikan tugas kepada para mahasiswa dan dosen pun bisa meng-upload materi dan tugas dimana saja dan kapan saja..
\end{abstract}

Kata kunci : e-learning, Pembelajaran, Logika Matematika

\section{ABSTRAK}

The development of information and communication technology (ICT) has brought enormous changes to the world of education. The form of development of information and communication technology that is applied in the world of education is an online learning method or better known as e-Learning that helps a learning process. Starting with a problem in learning methods and student interest in mathematics logic courses at the Faculty of Engineering UNIS Tangerang, an online learning (e-learning) method was developed using web-based object oriented methods using PHP and MYSQL. With this web-based online learning model can improve the learning process of students on ICT subjects and online learning makes it easier for lecturers to provide learning materials and give assignments to students and lecturers can upload materials and assignments anywhere and anytime ..

Keywords: e-learning, Learning, Mathematical Logic

\section{Pendahuluan}

\section{Latar Belakang}

Perkembangan teknologi informasi telah membawa perubahan yang sangat besar bagi dunia pendidikan. Seiring dengan perkembangan tersebut metode pembelajaran juga banyak mengalami perkembangan, baik metode pembelajaran secara personal, media pembelajaran ataupun proses pembelajaran. Bentuk perkembangan teknologi informasi yang diterapkan di dunia pendidikan adalah metode pembelajaran online atau lebih dikenal dengan sebutan E-Learning. E-Learning sebuah inovasi yang mempunyai kontribusi sangat besar terhadap perubahan proses pembelajaran, dimana proses pembelajaran tidak lagi hanya mendengarkan uraian materi dari Dosen tetapi Mahasiswa bisa melakukan aktivitas seperti mengamati, melakukan, mendemonstrasikan dan lain-lain. Materi bahan pembelajaran bisa 
Jurnal Keilmuan dan Aplikasi Teknik

UNISTEK, 2019, Vol. 6, No.2

divisualisasikan dalam berbagai format dan bentuk yang lebih dinamis dan interaktif sehingga murid akan termotivasi untuk terlibat lebih jauh dalam proses pembelajaran tersebut.

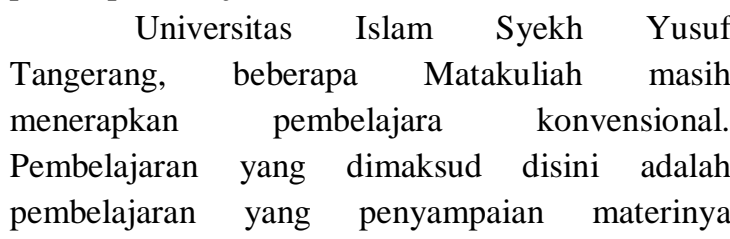
diuraikan oleh dosen dengan media pembelajaran yang masih standar, misalnya media pembelajaran menggunakan powerpoint atau tanpa media pembelajaran kemudian memberikan soal dengan materi yang terbatas. Berdasarkan uraian di atas dan dari pengamatan dan observasi yang saya lakukan dalam kurun waktu 3 Tahun belakang ini menunjukan secara umum bahwa mahasiswa mudah bosan dalam penyampaian materi yang monoton pada mata kuliah Logika Matematika . Memperhatikan hal tersebut, kemungkinan sistem yang digunakan dalam pembelajaran kurang tepat sehingga berpengaruh pada hasil belajar siswa.

Disisi lain, sarana dan prasarana yang dimiliki dikampus seperti jaringan internet kurang dioptimalkan. Hal ini dikarenakan kurang dimanfaatkannya internet sebagai media pembelajaran. Kampus belum memiliki ELearning, jadi dengan adanya media pembelajaran online atau E-Learning ini, diharapkan dapat meningkatkan proses pembelajar menjadi lebih kondusif, meningkatkan minat mahasiswa dalam belajar, serta meningkatkan hasil proses pembelajaran mahasisiswa. Hal ini dikareanakan $E$ Learning membawa mahasiswa untuk bisa berinteraksi dengan internet, seperti mengakses internet dengan luas, memunculkan sebuah ide kreatifitas siswa, serta ketersedian materi pembelajaran untuk siswa.

Penelitian ini dilaksanakan supaya motode pembelajaran pada mata kuliah Logika Matematika pada Fakultas Teknik Universitas Islam Syekh Yusuf Tangerang, dapat lebih berkembang melalui sebuah media pembelajaran E-Learning, sehingga peran dosen sebagai fasilitator dapat dilaksanakan dengan maksimal. Selain itu, kreatifitas siswa harus lebih ditekankan jika menggunakan media $E$ Learning, karena langkah pembelajaran yang telah diberikan dapat membuat siswa menjadi lebih mandiri dalam belajar dengan harapan mampu meningkatkan pemahaman siswa terhadap materi pelajaran yang diberikan, sehingga dapat meningkatkan proses pembelajaran dan hasil dari pembelajaran tersebut.

Berdasarkan latar belakang permasalahan

diatas, maka penulis berusaha mengimplementasikan "PROTOTIPE MODEL PEMBELAJARAN ONLINE DENGAN METODE OBJECT ORIENTED BERBASIS WEB (STUDI KASUS MATA KULIAH LOGIKA MATEMATIKA)”

\section{Identifikasi Masalah}

Berdasarkan hasil penelitian dan pengamatan penulis, Maka dari itu penulis mencoba untuk mengidentifikasi masalah sebagai berikut:

1. Keterbatasan pembelajaran berbasis teknologi komputer dan komunikasi.

2. Siswa membutuhkan akses belajar yang luas, aktif, kreatif dan menyenangkan.

3. Penggunaan internet belum optimal sebagai media pembelajaran.

4. Kurangnya ketertarikan dan minat siswa dalam mengikuti pelajaran Logika Matematika dan Algoritma Pemograman

5. Mengurangi eluangmahasiswa melakukan tindakan kurang terpuji yaitu mencontek.

\section{Rumusan Masalah}

Berdasarkan latar belakang diatas ada beberapa rumusan masalah yang dicantumkan:

1. Apakah dengan model pembelajaran online berbasis web ini dapat meningkatkan proses pembelajaran pada mata kuliah Logika Matematika?

2. Apakah prototipe sistem pembelajaran online akan memudakan dosen memberikan materi pembelajaran, memberikan tugas dan memberikan nilai kepada mahasiswa?

3. Bagaimana respon mahasiswa setelah menggunakan Sistem Aplikasi pembelajaran online ini?

\section{Batasan Masalah}

Agar penelitian dalam rencana proposal ini lebih terarah dan memudahkan dalam pembahasan, maka perlu adanya pembatasan masalah, yaitu : 
Jurnal Keilmuan dan Aplikasi Teknik

UNISTEK, 2019, Vol. 6, No.2

1. Dosen dapat meng-upload modul Matakuliah dan Mahasiswa dapat men-download modul tersebut.

2. Dosen dapat memberikan tugas melalui sistem pembelajaran online berbasis web tersebut.

3. Dosen dapat memberika ujian secara online dengan interval waktu yang di tentukan.

\section{Kegunaan Hasil Penelitian}

Kegunaan yang diharapkan dari penelitian ini adalah sebagai berikut :

1. Kegunaan Teoritis

Memberikan ilmu pengetahuan tentang model pembelajaran online berbasis web sebagai media pembelajaran yang tepat untuk meningkatkan proses pembelajaran pada mata mata kuliah Logika Matematika dan Algoritma Pemograman, serta dapat meningkatkan hasil belajar Mahasiswa

2. Kegunaan praktis

a. Bagi Dosen

1) Membantu Dosen dalam melaksanakan pembelajaran secara individual, interaktif dan kreatif dengan sumber yang luas.

2) Dosen dapat melakukan pengembangan potensi, gaya belajar, serta kebutuhan siswa yang beragam.

3) Dosen termotivasi untuk mengembangkan E-Learning.

4) Dosen dapat berperan sebagai fasilitator dalam pembelajaran.

b. Bagi Mahasiswa

1) Siswa dapat melakukan pembelajaran mata kuliah Logika Matematika dan dimana saja dan kapan saja, jika pembelajaran online atau E-Learning ini dimanfaatkan secara optimal.

2) Siswa memiliki sumber pembelajaran yang luas.

3) Siswa dapat belajar sesuai dengan kemampuan dan minatnya pada bidang mata mata kuliah Logika Matematika dan Algoritma Pemograman..

c. Bagi Fakultas

1) Tersedianya sumber pembelajaran alternatif yang dapat digunakan dalam kegiatan pembelajaran secara interaktrif.

2) Mendukung perkembangan teknologi di lingkungan Kampus

\section{Metode Penelitian}

Metode yang digunakan dalam penelitian ini yaitu metode waterfall. Model SDLC air terjun (waterfall) sering juga disebut model sekuensial linier (sequential linear) atau alur hidup klasik (classic life cycle). Model air terjun (waterfall) menyediakan pendekatan alur hidup perangkat lunak secara sekuensial atau terurut dimulai analisis, desain, pengodean, pengujian, dan tahap pendukung (support).

Berikut adalah gambar model air terjun (waterfall) :

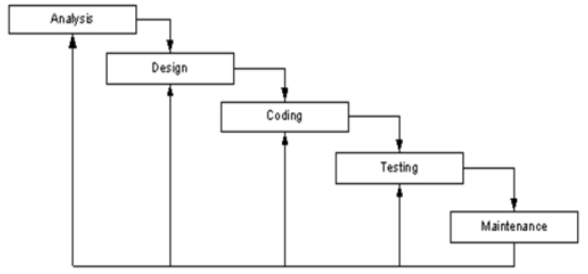

Gambar 1. Metode Waterfall

Penjelasan dari tahap-tahap penelitiannya :

1) Analisis kebutuhan perangkat lunak

Proses pengumpulan kebutuhan dilakukan secara intensif untuk menspe sifikasikan kebutuhan perangkat lunak agar dapat dipahami perangkat lunak seperti apa yang dibutuhkan user. Spesifikasi kebutuhan perangkat lunak pada tahap ini perlu untuk didokumentasikan.

2) Desain (perancangan)

Desain perangkat lunak adalah proses multi langkah yang fokus pada desain pembuatanprogram perangkat lunak termasuk struktur data, arsitektur perangkat lunak, representasi antar muka, dan prosedur pengodean. Tahap ini mentranslasi kebutuhan perangkat lunak dari tahap analisis kebutuhan ke representasi desain agar dapat diimplementasikan menjadi program pada tahap selanjutnya. Desain perangkat lunak yang dihasilkan pada tahap ini juga perlu didokumentasikan.

3) Pembuatan kode program 
Desain harus ditranslasikan kedalam program perangkat lunak. Hasil dari tahap ini adalah program komputer sesuai dengan desain yang telah dibuat pada tahap desain.

4) Pengujian

Pengujian fokus pada perangkat lunak secara dari segi lojik dan fungsional dan memastikan bahwa semua bagian sudah diuji. Hal ini dilakukan untuk meminimalisir kesalahan (error) dan memastikan keluaran yang dihasilkan sesuai dengan yang diinginkan.

5) Pendukung (support) atau pemeliharaan (maintenance)

Tidak menutup kemungkinan sebuah perangkat lunak mengalami perubahan ketika sudah dikirimkan ke user. Perubahan bisa terjadi karena adanya kesalahan yang muncul dan tidak terdeteksi saat pengujian atau perangkat lunak harus beradaptasi dengan lingkungan yang baru. Tahap pendukung atau pemeliharaan dapat mengulangi proses pengembangan mulai dari analisis spesifikasi untuk perubahan perangkat lunak yang sudah ada, tapi tidak untuk membuat perangkat lunak baru.

Model air terjun (waterfall) sangat cocok digunakan untuk kebutuhan pelanggan yang sudah sangat dipahami dan kemungkinan terjadinya perubahan kebutuhan selama pengembangan perangkat lunak kecil. Hal positif dari model air terjun (waterfall) adalah struktur tahap pengembangan sistem jelas, dokumentasi dihasilkan di setiap tahap pengembangan, dan sebuah tahap dijalankan setelah tahap sebelumnya selesai dijalankan.

Metode ini digunakan karena merupakan suatu metode yang praktis dan cukup menghemat biaya karena semua parameter-parameter yang dibutuhkan serta hasil yang diinginkan dapat langsung dimodelkan dan disimulasikan dengan menggunakan suatu program komputer (Personal Computer) dalam bentuk perangkat lunak berbasis sistem pakar.

\section{Teknik Pengumpulan Data}

Teknik pengumpulan data pada penelitian ini adalah:

1) penelitian kepustakaan, yaitu pengumpulan data melalui literature, makalah, laporan, jurnal, dan bahan kepustakaan lainnya yang terkait.

2) Observasi, yaitu pengumpulan data melalui pengamatan dan pengukuran langsung terhadap objek penelitian.

3) Literature Review, yaitu dimana mengambil referensi dari penelitian terdahulu yang sejenis

Untuk mencapai tujuan penelitian ini, maka data yang akan dikumpulkan meliputi data primer dan data sekunder. Data sekunder dikumpulkan berdasarkan parameter-parameter teoritis atau ilmiah yang menjadi dasar analisis. Sedangkan data primer diperoleh dari pengamatan langsung terhadap parameter kinerja yang mempengaruhi kinerja beberapa perangkat

\section{Perancangan User Interface}

1. Stuktur Tampilan

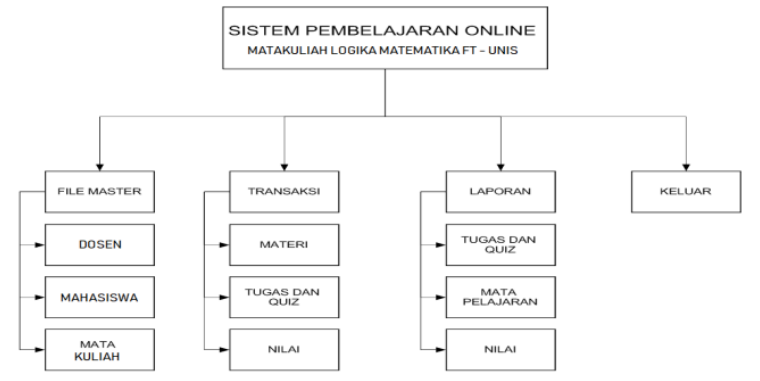

Gambar. 2 Struktur Tampilan

2. Rancangan Masukan (Input)

a. Menu Utama Dosen / Pengajar

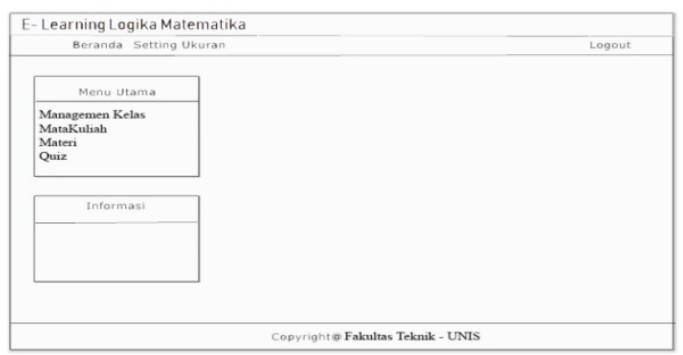

Gambar 3. Menu Utama Dosen/ Pengajar

b. Menu Utama Siswa

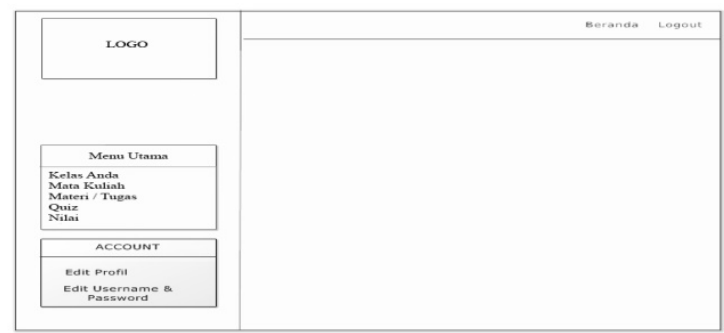

Gambar 4. Menu Utama Mahasiswa 
3. Rancamgan Keluaran (Output)

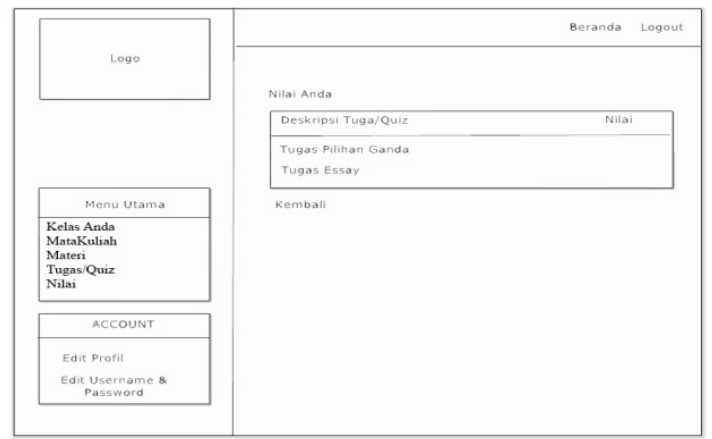

Gambar 5 Menu Rancangan Form Nilai

\section{Hasil Tampilan Program}

1. Login

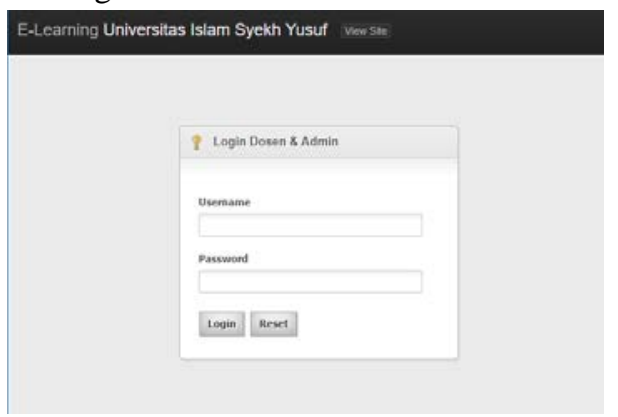

Gambar 6. Login Dosen dan Admin

Pada menu ini Admin dan Dosen memasukkan Username dan Password agar bias masuk pada menu utama.

5. Menu Utama Admin

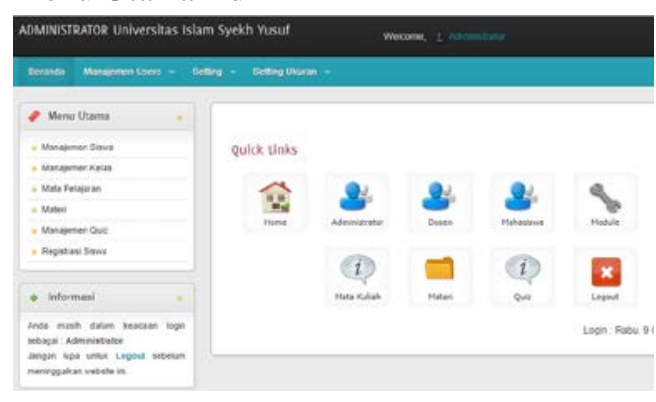

Gambar 7 . Menu Utama Admin dan Dosen

Pada Menu ini Ada beberapa Hal yang bisa di lakukan oleh Dosen/ Admin yaitu

a. Managemen Siswa

Pada Bagian ini Admin/ Dosen Bisa Menginput Mahasiswa yang akan menggunakan aplikasi ini. Sehingga nanti nya mahasiswa dapat mengakses semua item yang ada.

b. Managemen Kelas

Pada Bagian Ini Admin/ Dosen bias mengimput Kelas apa saja yang bisa mengakses Materi, Tugas/Quiz dan Nilai pada Form Mahasiswa.

c. Mata Kuliah

Pada Bagian Ini Admin/ Dosen bias mengimput Mata Kuliah/Pelajaran apa saja yang dapat menggunakan Aplikasi ini

d. Materi

Pada Bagian Ini Admin/ Dosen bisa mengupload Materi yang dapat di akses oleh Mahasiswa.

e. Managemen Quiz

Pada Bagian Ini Admin/ Dosen bias mengimput Kelas apa saja yang bisa mengakses Materi, Tugas/Quiz dan Nilai pada Form Mahasiswa

f. Registrasi Siswa

\section{DAFTAR PUSTAKA}

Firdaus, Muhammad Rizal. dkk. Pengembangan Sistem Informasi Penjualan Sepedah Motor Honda Menggunakan Metode Object Oriented Analys Design dengan Unified Approach. Vol. 10, No. 13. 2013.

Fathansyah. Basis Data. Bandung : Informatika Bandung, 2012.

Luthfi, Hisyam Wahid dan Berliana Kusuma Riasti. Sistem Informasi dan Perawatan Inventaris Laboraturium pada SMK Negeri 1 Rembang Berbasis Web. Jurnal Speed-Sentra Penelitian Engineering dan Edukasi, Vol. 3, No. 3, 2011.

Mahdiana, Deni. Analisa dan Rancangan Sistem Informasi Pengadaan Barang dengan Metodologi Berorientasi Objek. Jurnal TELEMATIKA MKOM, Vol. 3, No. 2, 2011.

Mubarok, Farid. dkk. Perbandingan Antara Metode RUP dan Prototype dalam Aplikasi Penerimaan Siswa Baru 
Berbasis Web. Citec Journal, Vol. 2, No. 2, 2015.

Ramadhan, Iqbal Chusni. Pengembangan Aplikasi E-Learning Berbasis Moddle. Jakarta: Universitas Islam Negri Jakarta, 2011.

Ramadhani, Mawar. Efektivitas Penggunaab Media Pembelajaran E-Learning Berbasis Web pada Pelajaran Teknologi Informasi dan Komunikasi Terhadap Hasil Belajar Siswa Kelas X SMA Negeri 1 Kalasan. Yogyakarta: Universitas Negeri Yogyakarta, 2012.

Susanti, Erma dan Muhammad Sholeh. Rancang Bangun Aplikasi E-Learning. Jurnal Teknologi, Volume 1, No. 1, hlm 5357, 2008.

Urva, Gellysa dan Helmi Fauzi Siregar. Pemodelan UML E-Marketing Minyak Goreng. Jurnal Teknologi dan Sistem Informasi, Volume 1, Nomor 2, hlm 92101, 2015.

Yazdi, Mohammad. E-Learning Sebagai Media Pembelajaran Interaktif Berbasis Teknologi Informasi. Jurnal Ilmiah Foristek Vol. 2, No. 1, 2012 